\title{
Loss of Expression of $\alpha 4 \beta 7$ Integrin and L-selectin Is Associated with High-Grade Progression of Low-Grade MALT Lymphoma
}

Yi-Xuan Liu, M.D., Tadashi Yoshino, M.D., Ph.D., Nobuya Ohara, M.D., Ph.D., Takashi Oka, Ph.D., Zai-Shun Jin, M.D., Kazuhiko Hayashi, M.D., Ph.D., Tadaatsu Akagi, M.D., Ph.D.

Second Department of Pathology, Okayama University Graduate School of Medicine and Denistry, Okayama, Japan

Expression of adhesion molecule in low-grade B-cell mucosa-associated lymphoid tissue (MALT) lymphoma of the gastrointestinal tract has been reported in recent years, but these reports have primarily focused on low-grade gastrointestinal MALT lymphoma. In this study, we examined the lymphocytic homing receptor $\alpha 4 \beta 7$ integrin, L-selectin, and VLA-4 and mucosal addressin cell adhesion molecule-1 (MAdCAM-1) in low-grade lymphoma of the gastrointestinal tract and other organs such as the ocular adnexa and thyroid. We also observed changes in the expression pattern associated with high-grade transformation. Neoplastic cells in the gastrointestinal low-grade lymphoma and the low-grade component of high-grade MALT lymphoma were found to be $\alpha 4 \beta 7$ integrin ${ }^{+}$, L-selectin $^{+}$, whereas the gastrointestinal high-grade component and diffuse large B-cell lymphoma were found to be $\alpha 4 \beta 7$ integrin $^{-}$, L-selectin ${ }^{-}$. High endothelial venules in the gastric MALT lymphomas expressed MAdCAM-1. In the ocular adnexa low-grade MALT lymphoma, most cases were $\alpha 4 \beta 7$ integrin $^{-}$, L-selectin $^{+}$; and in the thyroid, most cases of both low- and high-grade MALT lymphoma were $\alpha 4 \beta 7$ integrin $^{-}$, L-selectin ${ }^{-}$. These findings show that $\alpha 4 \beta 7$ integrin and L-selectin may play an important role in the lymphocyte homing of gastrointestinal low-grade MALT lymphoma and in the loss of $\alpha 4 \beta 7$ integrin expression throughout the course of highgrade progression.

Copyright () 2001 by The United States and Canadian Academy of Pathology, Inc.

VOL. 14, NO. 8, P. 798, 2001 Printed in the U.S.A.

Date of acceptance: March 30, 2001.

This work was supported in part by a Grant-in-Aid for Scientific Research from the Ministry of Education, Science, Sports and Culture of Japan (Grant-in-Aid for Exploratory Research 09877037).

Address reprint requests to: Tadaatsu Akagi, M.D., Ph.D., Department of Pathology, Okayama University Graduate School of Medicine and Dentistry, 2-5-1 Shikata-cho, Okayama, 700-8558, Japan; e-mail: akagi@cc.okayama-u.ac.jp; fax81-86-235-7156.
KEY WORDS: $\alpha 4 \beta 7$ integrin, Adhesion molecule, L-selectin, MALT lymphoma.

Mod Pathol 2001;14(8):798-805

Low-grade B-cell lymphomas of mucosa-associated lymphoid tissue (MALT) typically arise in extranodal organs that physiologically do not contain organized lymphoid tissues such as the gastrointestinal (G-I) tract, thyroid gland, orbits, salivary glands, respiratory tract, and genitourinary tract (1). MALT lymphomas tend to remain localized to the site of origin for long periods $(2,3)$. Lymph nodal involvement is rarely observed and only in cases of gastric low-grade MALT lymphoma invading the proper muscle layer of the stomach or deeper (4). However, MALT lymphomas sometimes disseminate to the MALT without lymph node involvement (5-7), as cutaneous lymphomas tend to spread to the skin without lymph nodal lesions. These observations imply that mechanisms controlling normal mucosal lymphocyte traffic may also be operational in MALT lymphomas.

Lymphocyte homing into the selective lymphoid tissues is regulated by adhesion molecules expressed by the lymphocytes (homing receptors) and their endothelial ligands, vascular addressins $(8,9)$. It has been shown in mice that $\alpha 4 \beta 7$ integrin, which is expressed on mucosal lymphocytes, primarily mediates lymphocyte traffic to the intestinal mucosa through interactions with mucosal addressin cell adhesion molecule-1 (MAdCAM-1), which is expressed on high endothelial venules (HEVs) in the gut-associated lymphoid tissues (GALT; 10, 11). This has also been found to be the case in humans (12). The human $\alpha 4 \beta 7$ integrin is widely expressed by leukocyte subsets in the peripheral blood, organized lymphoid tissue, intestinal lamina propria, and lung parenchyma (12-17). Its corresponding ligand, human MAdCAM-1, has recently been cloned and found to be expressed primarily in the small intestine and, to a lesser 


\begin{tabular}{|c|c|c|c|}
\hline Specificity & Clone & Isotype & Source \\
\hline \multirow[t]{2}{*}{ Human MAdCAM-1 } & 10G3 & & Dr. M. J. Briskin, LeukoSite Inc. \\
\hline & $10 \mathrm{~A} 6$ & & Dr. M. J. Briskin \\
\hline$\alpha 4 \beta 7$ integrin & ACT-1 & mouse IgG1 & Dr. M. J. Briskin \\
\hline \multirow[t]{2}{*}{ L-selectin (CD62L) } & DREG-56 & mouse IgG1 & Endogen Woburn, MA \\
\hline & FMC46 & mouse IgG2b & Novocastra Laboratories, Tyne, UK \\
\hline VLA-4 $\alpha$ chain (CD49d) & SG/73 & mouse IgG1 kappa & Seikagaku, Tokyo, Japan \\
\hline CD20-FITC & B-Ly1 & IgG1 kappa & DAKO, Glostrup, Denmark \\
\hline CD3-FITC & UCHT1 & IgG1 kappa & DAKO \\
\hline
\end{tabular}

TABLE 2. Expression of $\alpha 4 \beta 7$ Integrin, L-Selectin, and VLA-4 in Gastrointestinal, Occular Adnexal, and Thyroid Lymphoma

\begin{tabular}{|c|c|c|c|c|}
\hline \multirow{2}{*}{ Organ } & \multirow{2}{*}{ Type of Lymphoma } & \multicolumn{3}{|c|}{ Expression of Adhesion Molecules } \\
\hline & & $\alpha 4 \beta 7$ integrin & L-selectin & VLA-4 \\
\hline \multirow[t]{5}{*}{ Stomach } & Low-grade MALT lymphoma & $19 / 19^{a}$ & $16 / 19$ & $4 / 17$ \\
\hline & High-grade MALT lymphoma & & & \\
\hline & low-grade component & $4 / 5$ & $4 / 5$ & $1 / 5$ \\
\hline & high-grade component & $0 / 5$ & $1 / 5$ & $1 / 5$ \\
\hline & DLBL & $0 / 8$ & $4 / 8$ & $0 / 8$ \\
\hline \multirow[t]{2}{*}{ Intestine } & Low-grade MALT lymphoma & $3 / 3$ & $2 / 3$ & $1 / 3$ \\
\hline & DLBL & $0 / 6$ & $0 / 6$ & $0 / 6$ \\
\hline Occular & Low-grade MALT lymphoma & $3 / 10$ & $8 / 10$ & $2 / 10$ \\
\hline adnexa & DLBL & $2 / 4$ & $2 / 4$ & $1 / 4$ \\
\hline \multirow[t]{5}{*}{ Thyroid } & Low-grade MALT lymphoma & $2 / 9$ & $2 / 9$ & $2 / 9$ \\
\hline & High-grade MALT lymphoma & & & \\
\hline & low-grade component & $0 / 4$ & $0 / 4$ & $0 / 4$ \\
\hline & high-grade component & $0 / 4$ & $0 / 4$ & $0 / 4$ \\
\hline & DLBL & $0 / 1$ & $0 / 1$ & $0 / 1$ \\
\hline
\end{tabular}

Expression of $\alpha 4 \beta 7$ integrin and L-selectin in low-grade gastric MALT lymphoma and low-grade components of high-grade gastric MALT lymphoma are significantly higher than in high-grade components of high-grade gastric MALT lymphoma ( $\alpha 4 \beta 7$ integrin, $P<.01 ;$ L-selectin, .01 $<P<.05)$. DLBL, diffuse large B-cell lymphoma; MALT, mucosa-associated lymphoid tissue.

${ }^{a}$ No. of positive cases/no. of examined cases. DLBL, diffuse large B-cell lymphoma.

extent, in the colon and spleen $(18,19)$. Malignant lymphomas are expected to show the same expression pattern as that observed in corresponding counterparts of the nonneoplastic lymphoid tissues. In fact, $\alpha 4 \beta 7$ integrin is preferentially expressed in gastrointestinal low-grade MALT lymphomas (28). $\alpha 4$ integrin is also expressed on leukocytes as a heterodimeric integrin with the $\beta 1$ integrin chain. $\alpha 4 \beta 1$ (VLA-4) is a ligand for VCAM-1 (20) and is involved in B-lymphocyte adhesion to germinal centers (21) but is not involved in lymphocyte homing to mucosal sites.

L-selectin regulates lymphocyte homing to the peripheral lymph node through interactions with the peripheral lymph node vascular addressin (PNAd) expressed on HEVs $(8,22)$. PNAds include GlyCAM-1 (23) and CD34 (24). Furthermore, L-selectin has been shown to bind to sialyl-Lewis ${ }^{\mathrm{x}}$ (25), which is also expressed on human HEV (26), and to a mucinlike domain of MAdCAM-1 (27). Therefore, it is possible that L-selectin is also involved in mucosal lymphocyte trafficking. L-selectin is expressed on germinal-center B cells and is consistently expressed on mantle zone B-cells (29). Although extrafollicular B cells and plasma cells in tonsils and lymph nodes are L-selectin positive, those within the lamina propria of gastrointestinal tract show a variable expression of L-selectin (29). As for malignant lymphomas, it has been reported that 50 to $80 \%$ of low-grade gastric lymphomas express L-selectin $(29,30)$.

Recent studies have revealed expression of $\alpha 4 \beta 7$ integrin and L-selectin in G-I MALT lymphomas (28-30), but there are few data about the homing receptors in MALT lymphomas of other organs. In the present study, we examined the expression patterns of $\alpha 4 \beta 7$ integrin, L-selectin, and VLA- 4 in MALT lymphomas of the G-I tract, thyroid, and ocular adnexa. We also identified changes in their expression pattern associated with the high-grade transformation of low-grade MALT lymphoma.

\section{MATERIALS AND METHODS}

\section{Tissue Samples}

We examined 41 cases of low-grade MALT lymphoma (19 gastric, 3 intestinal, 10 ocular adnexal, and 9 thyroid), 9 cases of high-grade MALT lymphoma (5 gastric and 4 thyroid), and 19 cases of diffuse large B-cell lymphoma (DLBL; 8 gastric, 6 intestinal, 4 ocular adnexal, and 1 thyroid) selected from the files of the Second Department of Pathology, Okayama University Medical School. Low- 
grade MALT lymphomas were diagnosed according to the criteria described by Isaacson (1; Fig. 1A-B). We defined high-grade MALT lymphomas as combined lymphomatous foci of high-grade as well as low-grade components (Fig. 2A and D). Fresh tissue samples were obtained from the surgically resected materials, snap-frozen in liquid nitrogen, and stored at $-80^{\circ} \mathrm{C}$ until used. For histopathological diagnosis, the tissue specimens were fixed in buffered formalin and paraffin embedded.

\section{Immunohistochemistry}

Immunohistochemical staining was performed on acetone-fixed cryostat sections for $\alpha 4 \beta 7$ integrin, L-selectin, and VLA-4 or on formalin-fixed, paraffin-embedded sections for MAdCAM-1 by the indirect immunoperoxidase method using dextran polymer-conjugated secondary antibody labeled with peroxidase (EnVision ${ }^{+}$, DAKO Japan, Kyoto, Japan). In brief, 4-6- $\mu$ m-thick sections were blocked with $10 \%$ goat serum or $10 \%$ skim milk and then incubated with the primary antibodies listed in Table 1 for 90 minutes at room temperature. The specimens were then treated with the EnVision ${ }^{+}$ immunostaining system according to the manufacturer's instructions. Diaminobenzidine was used for color development, and hematoxylin, for counterstaining.

For double immunofluorescence, acetone-fixed frozen sections were blocked with $10 \%$ skim milk for 15 minutes and then treated with anti- $\alpha 4 \beta 7$ integrin monoclonal antibody (mAb) for 90 minutes at room temperature. After washing with $0.05 \%$ Tween 20-containing phosphate buffered saline (Tween-PBS), the specimens were treated with 1:100-diluted rhodamine-labeled goat (Fab') 2 antimouse IgG (Leinco Technologies Inc., Ballwin, MO) for 30 minutes at room temperature. After washing with Tween-PBS and blocking with $10 \%$ normal mouse serum, they were treated with fluorescence isothiocyanate-labeled anti-CD 20 or anti-CD3 mAbs (DAKO) for 30 minutes at room temperature. Haexist 1:500 was used for nuclear staining. Simultaneous detection of both $\alpha 4 \beta 7$ integrin and L-selectin was performed by the double immunofluorescence method, as described elsewhere (31).
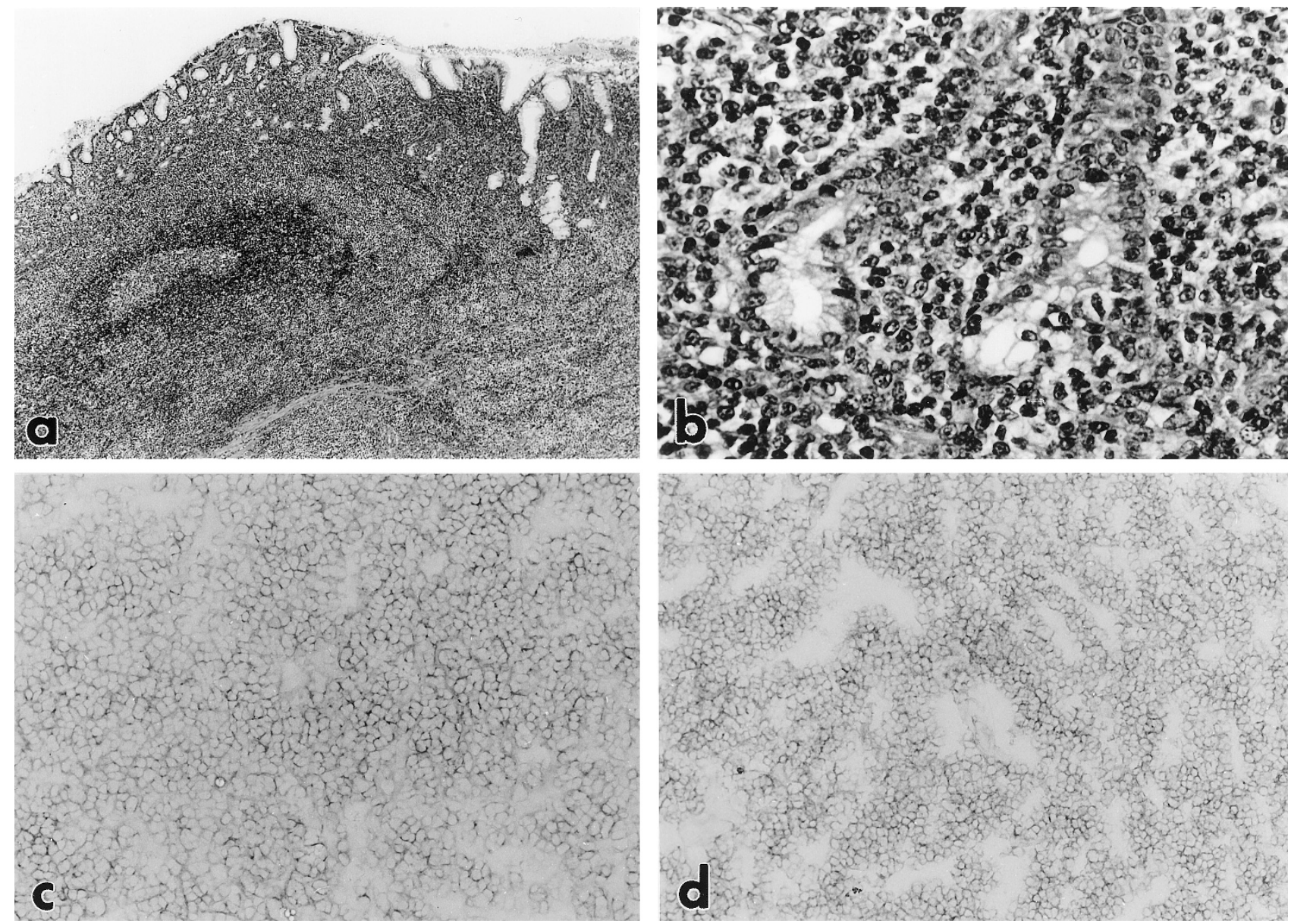

FIGURE 1. Immunohistochemical staining of $\alpha 4 \beta 7$ integrin and L-selectin in the low-grade gastric MALT lymphoma. A and B, histological features, $35 \times, 370 \times$. C, $\alpha 4 \beta 7$ integrin, $160 \times$; D, L-selectin, $160 \times$. 


\section{Statistical Analysis}

A statistical comparison of $\alpha 4 \beta 7$ integrin or L-selectin immunoreactivity was performed by the $\chi^{2}$ test using a statistical software package (Fisher's exact test).

\section{RESULTS}

\section{Expression of $\alpha 4 \beta 7$ Integrin in MALT Lymphoma}

The immunoreactivity of MALT lymphomas and DLBL for $\alpha 4 \beta 7$ integrin, L-selectin, and VLA- 4 is summarized in Table 2. Most of the low-grade gastric MALT lymphoma and a low-grade component of high-grade gastric MALT lymphoma were positive for $\alpha 4 \beta 7$ integrin (Fig. 1C and 2B). In contrast, a high-grade component of high-grade MALT lymphoma and DLBL rarely expressed $\alpha 4 \beta 7$ integrin (Fig. 2E), and this difference was statistically significant. $\alpha 4 \beta 7$ integrin was also found to be expressed in all cases of intestinal low-grade MALT lymphoma and in a small proportion of ocular adnexal and thyroid low-grade lymphoma. Nonneoplastic plasma cells in the lamina propria were positive for $\alpha 4 \beta 7$ integrin but negative for L-selectin. Some T cells were also positive for $\alpha 4 \beta 7$ integrin. MALT lymphoma cells frequently show plasmacytic differentiation and are sometimes intermingled with many reactive $\mathrm{T}$ cells; it is therefore critically important to determine whether $\alpha 4 \beta 7$ integrinpositive cells are centrocyte-like cells of MALT lymphoma, nonneoplastic plasma cells, or intermingled $\mathrm{T}$ cells. For this purpose, gastric lowgrade MALT lymphoma tissues were immunostained by the double immunofluorescence method using fluorescence isothiocyanate-labeled anti-CD3 or CD20 mAb and anti- $\alpha 4 \beta 7$ integrin mAb combined with rhodamine-labeled anti-mouse IgG antibody. Figure 3A-B clearly shows that most $\alpha 4 \beta 7$

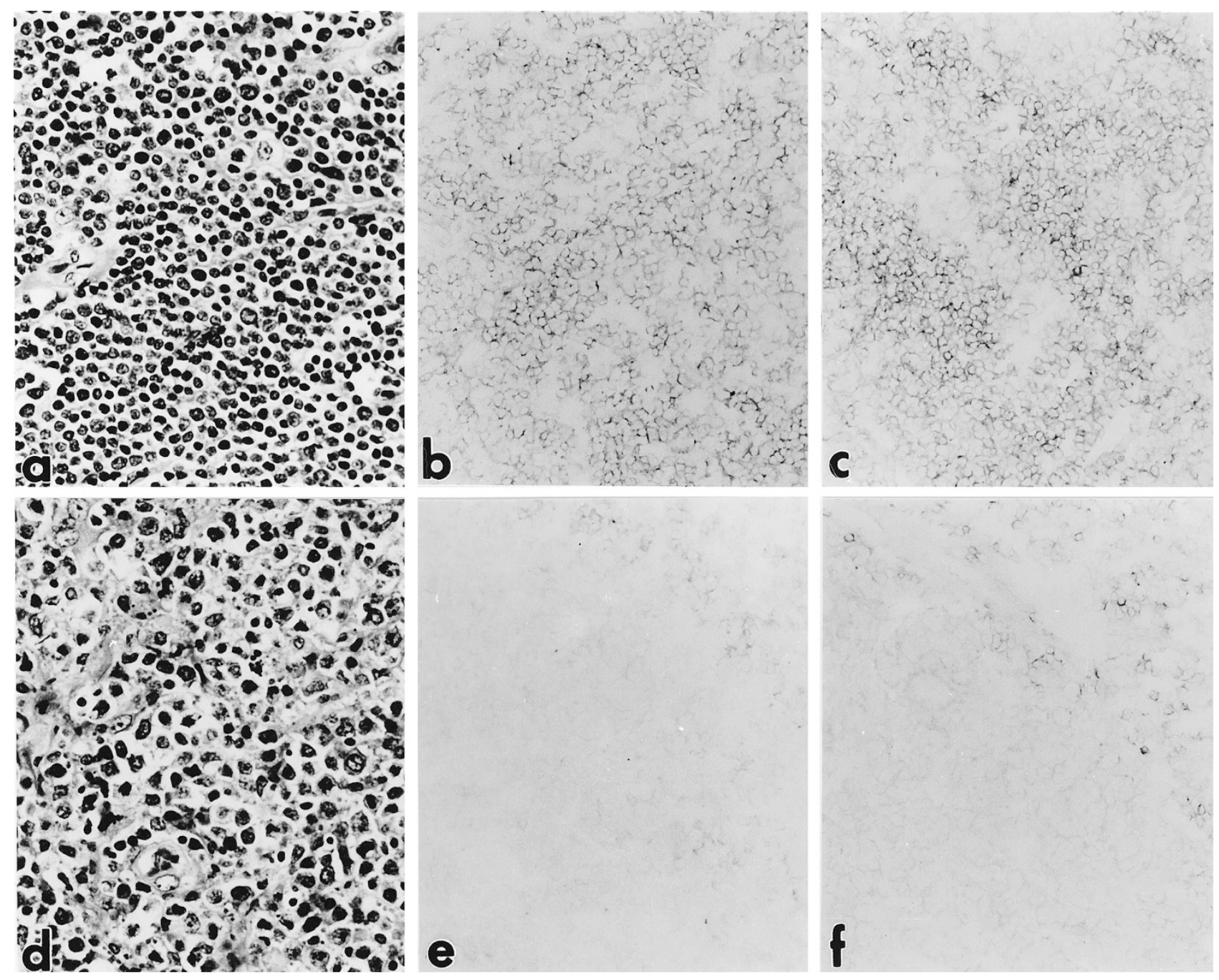

FIGURE 2. Immunohistochemical staining of $\alpha 4 \beta 7$ integrin and L-selectin in the high-grade gastric MALT lymphoma. A-C, low-grade components; D-F, high-grade components. A and D, histological pictures, $270 \times$; B and E, $\alpha 4 \beta 7$ integrin, $160 \times$; C and F, L-selectin, $160 \times$. The high-grade components of high-grade MALT lymphoma are negative for either $\alpha 4 \beta 7$ integrin or L-selectin (E and $\mathbf{F}$ ), whereas intermingled low-grade components and some intermingled nonneoplastic lymphocytes (upper right field) show positive immunoreactivity. 

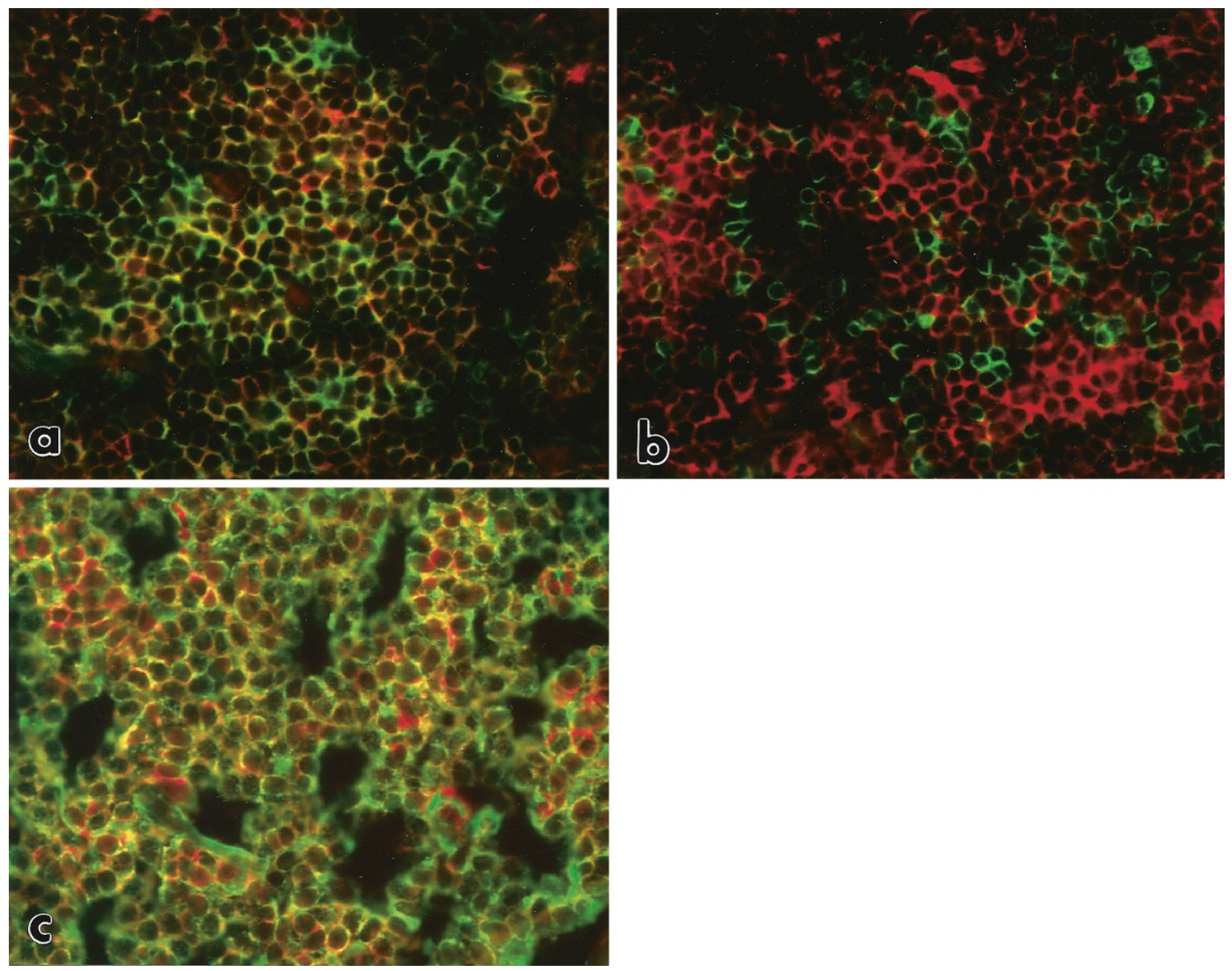

FIGURE 3. Double immunofluorescence for $\alpha 4 \beta 7$ integrin and CD20, CD3, or L-selectin in low-grade gastric MALT lymphoma. (a), $\alpha 4 \beta 7$ (rhodamine), and CD20 (fluorescence isothiocyanate), $400 \times$. (b), $\alpha 4 \beta 7$ (rhodamine) and CD3 (fluorescence isothiocyanate), $400 \times$. (c), $\alpha 4 \beta 7$ (fluorescence isothiocyanate) and L-selectin (rhodamine), $600 \times$. Double-positive cells are stained orange.

integrin-positive cells were concomitantly positive for CD20 and negative for CD3; they were thus easily discriminated from intermingled small-sized $\mathrm{T}$ cells.

\section{Expression of L-Selectin in MALT Lymphomas}

We used two kinds of mAbs to L-selectin, DREG-56 and FMC46; FMC46 showed better reactivity, and the stainability of the specimens was evaluated from the results of staining with FMC46 (Table 2). L-selectin was frequently expressed in low-grade MALT lymphoma of the G-I tract and ocular adnexa and in a low-grade component of high-grade gastric MALT lymphoma (Figs. 1D and 2C), in contrast, a high-grade component of gastric high-grade MALT lymphoma tended to lose L-selectin expression (Fig. 2F). Low-grade MALT lymphomas of the thyroid infrequently expressed L-selectin, with L-selectin being detected in half of DLBL cases of the stomach and ocular adnexa but in none of DLBL cases of the gut and thyroid.

\section{Expression of VLA-4 in MALT Lymphomas}

VLA4 was detected in only a small proportion of the cases examined, but especially in cases of lowgrade MALT lymphoma (Table 2). In gastric lowgrade MALT lymphomas, three of four VLA $-4^{+}$ cases were also positive for both $\alpha 4 \beta 7$ integrin and L-selectin.

\section{Coexpression of $\alpha 4 \beta 7$ Integrin and L-Selectin}

In the low-grade MALT lymphomas of the G-I tract, all 22 cases examined expressed $\alpha 4 \beta 7$ integrin, and 18 cases also expressed L-selectin. In the ocular adnexa and thyroid, approximately half of the cases of low-grade MALT lymphoma expressed either $\alpha 4 \beta 7$ integrin or L-selectin. In the cases expressing both $\alpha 4 \beta 7$ integrin and L-selectin, both adhesion molecules were primarily coexpressed at individual cellular levels, as evidenced by the double immunostaining (Fig. 3C), and only a few $\alpha 4 \beta 7$ integrin -positive cells were negative for L-selectin 2 . 


\section{Expression of MAdCAM-1}

MAdCAM-1 was consistently expressed on HEVs in the gastric mucosa of chronic gastritis and also in the lymphomatous lesions of gastric MALT lymphoma but not on HEVs in gastric DLBL (Fig. 4). HEVs in low-grade MALT lymphoma tissues of the ocular adnexa were negative for MAdCAM-1. In the thyroid, most lesions of chronic thyroiditis and about a half of low-grade MALT lymphoma lesions expressed MAdCAM-1 on the HEVs (data not shown).

\section{DISCUSSION}

In this study, we observed preferential expression of $\alpha 4 \beta 7$ integrin and L-selectin on lymphoma cells of low-grade MALT lymphoma and low-grade components of high-grade MALT lymphoma of the G-I tract. Plasma cells in the lamina propria of the human stomach and small intestine strongly expressed $\alpha 4 \beta 7$ integrin but were negative for L-selectin, as described elsewhere (30). Dogan et al. (30) have reported that the majority of marginalzone B cells of the human GALT express low levels of $\alpha 4 \beta 7$ integrin and high levels of L-selectin. MALT lymphoma cells are derived from marginal-zone B cells of the memory phenotype. Therefore, it is reasonable that low-grade MALT lymphoma cells of the G-I tracts consistently expressed variable levels of $\alpha 4 \beta 7$ integrin and L-selectin. HEVs in the nonlymphomatous G-I mucosa and gastric MALT lymphoma tissues were positive for MAdCAM-1 as reported (30; Fig. 4). The interaction between the $\alpha 4 \beta 7$ integrin expressed by lymphocytes and MAdCAM-1 expressed by HEVs mediates lymphocyte homing to GALTs. This physiological homing mechanism may also function in MALT lymphomas and may explain the biological characteristic of MALT lymphomas in which they tend to remain localized to the site of origin for long periods.

Our results showing that low-grade MALT lymphoma cells of the G-I tract consistently express $\alpha 4 \beta 7$ integrin are comparable with those reported previously by Drillenburg et al. (28). High-grade components of gastric MALT lymphoma and DLBL cells were found to be consistently negative for $\alpha 4 \beta 7$ integrin. Thus, G-I MALT lymphoma cells may lose their expression of $\alpha 4 \beta 7$ integrin after progres-
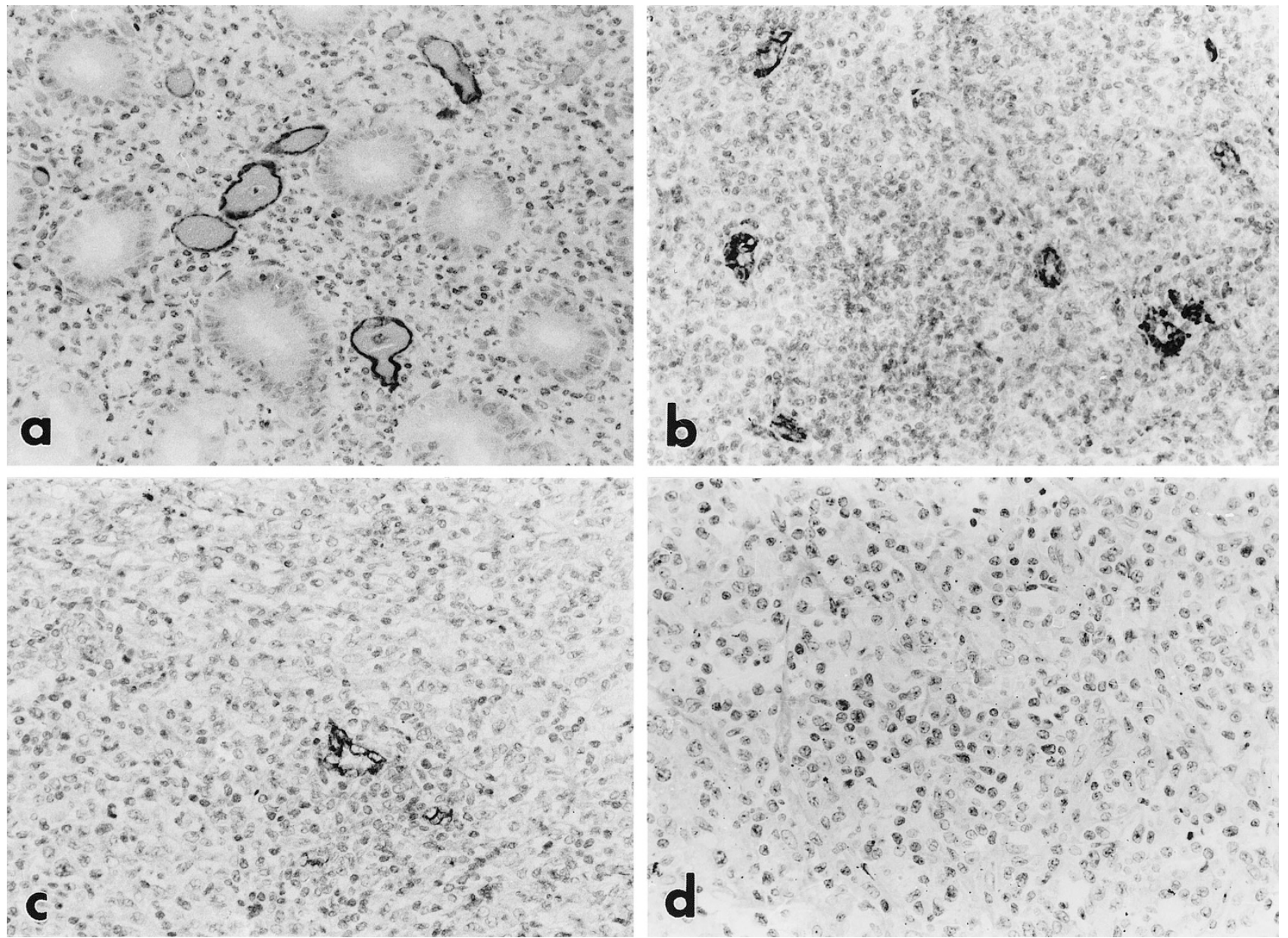

FIGURE 4. Immunohistochemical staining of MAdCAM-1 in the gastric mucosa of chronic gastritis (A) and in the lymphomatous lesions of lowgrade MALT lymphoma (B), high-grade MALT lymphoma (C), and DLBL (D) of the stomach, $220 \times$. 
sion to a high-grade malignancy. L-selectin was also found to be less frequently expressed in highgrade than in low-grade MALT lymphoma cells.

In contrast to the present data, Dogan et al., 30) have reported that low-grade MALT lymphoma cells in the stomach are $\alpha 4 \beta 7$ integrin $^{-}$, L-selectin ${ }^{+}$, whereas the intestinal secondary lymphoma cells are $\alpha 4 \beta 7$ integrin $^{+}$, L-selectin ${ }^{-}$. They claimed that $\alpha 4 \beta 7$ integrin positivity in gastric low-grade MALT lymphoma may be overestimated by the presence of $\alpha 4 \beta 7$ integrin $^{+}$plasma cells in the lamina propria and that $\alpha 4 \beta 7$ integrin $^{+}$reactive $\mathrm{T}$ cells intermingling with lymphoma cells. In fact, some cases of gastric low-grade MALT lymphoma have shown substantial numbers of reactive $T$ cells. In our series, however, lymphomatous lesions with only a few intermingled $\mathrm{T}$ cells also showed $\alpha 4 \beta 7$ integrin positivity. Even in the T cell-rich area, double immunofluorescent staining of $\mathrm{CD} 3 / \alpha 4 \beta 7$ integrin and $\mathrm{CD} 20 / \alpha 4 \beta 7$ integrin showed that $\mathrm{CD} 20^{+} \mathrm{B}$ cells were positive for $\alpha 4 \beta 7$ integrin.

In the ocular adnexa and thyroid, $\alpha 4 \beta 7$ integrin was less frequently expressed, even in low-grade MALT lymphomas. This evidence suggests that another homing system may operate in these organs, although MAdCAM-1 is frequently expressed in HEVs of the thyroid. VLA-4 was expressed only in a small proportion of low-grade MALT lymphomas and in none of the DLBL. Therefore, VLA-4 may not play a major role in the growth of lymphoma in the mucosal site.

In conclusion, the present study shows that $\alpha 4 \beta 7$ integrin and L-selectin may be involved in the mucosal homing of low-grade MALT lymphoma cells in the G-I tract and that the expression of $\alpha 4 \beta 7$ integrin is lost in the course of high-grade progression.

Acknowledgments: We thank Dr. M.J. Briskin of LeukoSite Inc. for the generous gift of monoclonal antibody MAdCAM-1. We are also thankful to the Okayama University Medical School Hospital and the Aichi Cancer Center for providing the cases materials. We also thank Ms. Motochika for her help with the photography and Ms. Okabe for her help with the immunohistochemistry.

\section{REFERENCES}

1. Isaacson PG, Norton AJ. Mucosa-associated lymphoid tissue (MALT) and the MALT lymphoma concept. In: Isaacson PG, Norton AJ, editors. Extranodal lymphomas. Edinburgh, United Kingdom: Churchill Livingstone; 1994. p. 5-14.

2. Isaacson PG. Gastrointestinal lymphoma. Hum Pathol 1994; 25:1020-9.

3. Krol AD, Hermans J, Kramer MH, et al. Gastric lymphomas compared with lymph node lymphomas in a populationbased registry differ in stage distribution and dissemination pattern but not in patient survival. Cancer 1997;79:390-7.
4. Yoshino T, Akagi T. Gastric low-grade mucosa-associated lymphoid tissue lymphomas: their histogenesis and highgrade transformation. Pathol Int 1998;48:323-31.

5. Du MQ, Xu CF, Diss TC, Peng HZ, Wotherspoon AC, Isaacson PG, Pan LX. Intestinal dissemination of gastric mucosaassociated lymphoid tissue lymphoma. Blood 1996;88:444551.

6. Mattia AR, Ferry JA, Harris NL. Breast lymphoma: a B-cell spectrum including the low-grade B-cell lymphoma of mucosa-associated lymphoid tissue. Am J Surg Pathol 1993; 17:574-87.

7. Di Loreto C, Mariuzzi L, De Grassi A, Beltrami CA. B cell lymphoma of the thymus and salivary gland. J Clin Pathol 1996;49:595-7.

8. Picker LJ, Butcher EC. Physiological and molecular mechanisms of lymphocyte homing. Annu Rev Immunol 1992;10: 561-91.

9. Butcher EC, Picker LJ. Lymphocyte homing and homeostasis. Science 1996;272:60-6.

10. Holzmann B, McIntyre BW, Weissman IL. Indentification of a murine Peyer's patch-specific lymphocyte homing receptor as an integrin molecule with an $\alpha$ chain homologous to human VLA-4 $\alpha$. Cell 1989;56:37-46.

11. Berlin C, Berg EL, Briskin MJ, Andrew DP, Kilshaw PJ, Holzmann B, et al. $\alpha 4 \beta 7$ integrin mediates lymphocyte binding to the mucosal vascular addressin MAdCAM-1. Cell 1993;74: 185-95.

12. Erle DJ, Briskin MJ, Butcher EC, Garcia Pardo A, Lazarovits AI, Tidswell M. Expression and function of the MAdCAM-1 receptor, integrin $\alpha 4 \beta 7$, on human leukocytes. J Immunol 1994;153:517-28.

13. Schweighoffer T, Tanaka Y, Tidswell M, Erle DJ, Horgan KJ, Luce GE, et al. Selective expression of integrin $\alpha 4 \beta 7$ on a subset of human CD4+ memory T cells with hallmarks of gut-trophism. J Immunol 1993;151:717-29.

14. Postigo AA, Sanchez-Mateos P, Lazarovits AI, SanchezMadrid F, de Landazuri MO. $\alpha 4 \beta 7$-integrin mediate B cell binding to fibronectin and vascular cell adhesion molecule 1. Expression and function of $\alpha 4$ integrins on human $\mathrm{B}$ lymphocytes. J Immunol 1993;151:2471-83.

15. Tiisala S, Paavonen T, Renkonen R. $\alpha \mathrm{E} \beta 7$ and $\alpha 4 \beta 7$ integrins associated with intraepithelial and mucosal homing, are expressed on macrophages. Eur J Immunol 1995;25:411-7.

16. Farstad IN, Halstensen TS, Lazarovits AI, Norstein J, Fausa O, Brandtzaeg P. Human intestinal B-cell blasts and plasma cells express the mucosal homing rectptor integrin $\alpha 4 \beta 7$. Scand J Immunol 1995;42:662-72.

17. Farstad IN, Halstensen TS, Kvale D, Fausa O, Brandtzaeg P. Topographic distribution of homing receptors of $\mathrm{B}$ and $\mathrm{T}$ cells in human gut-associated lymphoid tissue: relation of L-selectin and integrin $\alpha 4 \beta 7$ to naive and memory phenotypes. Am J Pathol 1997;150:187-99.

18. Shyjan A, Bertagnolli M, Kenney C, Briskin M. Human mucosal addressin cell adhesion molecule-1 (MAdCAM-1) demonstrates structural and functional similarities to the $\alpha 4 \beta 7$ integrin binding domain of murine MAdCAM-1, but extreme divergence of mucin-like sequences. J Immunol 1996;156: 2851-7.

19. Briskin M, Winsor-Hines D, Shyjan A, Cochran N, Bloom S, Wilson $\mathrm{J}$, et al. Human mucosal addressin cell adhesion molecule-1 is preferentially expressed in intestinal tract and associated lymphoid tissue. Am J Pathol 1997;151:97-110.

20. Elices MJ, Osborn L, Takada Y, Crouse C, Luhowskyj S, Hemler ME, et al. VCAM-1 on activated endothelium interacts with the leukocyte integrin VLA-4 at a site distinct from the VLA-4/fibronectin binding site. Cell 1990;60:577-84.

21. Freedman AS, Munro JM, Rice GE, Bevilacqua MP, Morimoto C, McIntyre BW, et al. Adhesion of human B cells to 
germinal centers in vitro involves VLA-4 and INCAM-110. Science 1990;249:1030-3.

22. Berg EL, Robinson MK, Warnock RA, Butcher EC. The human peripheral lymph node vascular addressin is a ligand for LECAM-1, the peripheral lymph node homing receptor. J Cell Biol 1991;114:343-9.

23. Lasky LA, Singer MS, Dowbenko D, Imai Y, Henzel WJ, Grimley $\mathrm{C}$, et al. An endothelial ligand for L-selectin is a novel mucin-like molecule. Cell 1992;69:927-38.

24. Baumheter S, Singer MS, Henzel W, Hemmerich S, Renz M, Rosen SD, et al. Binding of L-selectin to the vascular sialomucin CD34. Science 1993;262:436-8.

25. Foxall C, Watson SR, Dowbenko D, Fennie C, Lasky LA, Kiso $\mathrm{M}$, et al. The three members of the selectin receptor family recognize a common carbohydrate epitope, the sialyl Lewis(x) oligosaccharide. J Cell Biol 1992;117:895-902.

26. Munro JM, Lo SK, Corless C, Robertson MJ, Lee NC, Barnhill $\mathrm{RL}$, et al. Expression of sialyl-Lewis ${ }^{\mathrm{x}}$, an E-selectin ligand, in inflammation, immune responses, and lymphoid tissues. Am J Pathol 1992;141:1397-408.

27. Berg EL, McEvoy LM, Berlin C, Bargatze RF, Butcher EC.
L-selectin-mediated lymphocyte rolling on MAdCAM-1. Nature 1993;366:695-8.

28. Drillenburg P, van der Voort R, Koopman G, Dragosics B, van Krieken JH, Kluin $\mathrm{P}$, et al. Preferential expression of the mucosal homing receptor integrin $\alpha 4 \beta 7$ in gastrointestinal non-Hodgkin's lymphomas. Am J Pathol 1997;150:919-27.

29. Möller P, Eichelmann A, Mechtersheimer G, Koretz K. Expression of $\beta 1$-integrins, H-CAM (CD44) and LECAM- 1 in primary gastrointestinal $\mathrm{B}$-cell lymphomas as compared to the adhesion receptor profile of the gut-associated lymphoid system, tonsil and peripheral lymph node. Int J Cancer 1991; 49:846-55.

30. Dogan A, Du M, Koulis A, Briskin MJ, Isaacson PG. Expression of lymphocyte homing receptors and vascular addressins in low-grade gastric B-cell lymphomas of mucosa-associated lymphoid tissue. Am J Pathol 1997;151: 1361-9.

31. Teramoto N, Szekely L, Pokrovskaja K, Hu LF, Yoshino T, Akagi T, et al. Simultaneous detection of two independent antigens by double staining with two mouse monoclonal antibodies. J Virol Methods 1998;73:89-97. 